\title{
Effectiveness of a Physical Strength Improvement System in School-Age Children Based on the Action Plan of City $\mathrm{O}$
}

\author{
Ken-ichi Watanabe ${ }^{1,}$, Keiko Abe $^{1}$, Takafumi Yamate $^{2}$, Kan-ichi Mimura ${ }^{1}$, Katsunori Fujii ${ }^{3}$ \\ ${ }^{1}$ Faculty of Education, Osaka Seikei University, Osaka-City, Japan \\ ${ }^{2}$ Faculty of Sport Study, Biwako Seikei Sport College, Otsu-City, Japan \\ ${ }^{3}$ Graduate School of Business Administration and Computer Science, Aichi Institute of Technology, Toyota-City, Japan
}

Email address:

watanabe-k@osaka-seikei.ac.jp (Ken-ichi W.), abe-ke@osaka-seikei.ac.jp (Keiko A.), yamate@bss.ac.jp (Takafumi Y.), mimura@osaka-seikei.ac.jp (Kan-ichi M.), fujii@aitech.ac.jp (Kastunori F.)

${ }^{*}$ Corresponding author

\section{To cite this article:}

Ken-ichi Watanabe, Keiko Abe, Takafumi Yamate, Kan-ichi Mimura, Katsunori Fujii. Effectiveness of a Physical Strength Improvement System in School-Age Children Based on the Action Plan of City O. American Journal of Sports Science. Vol. 9, No. 2, 2021 , pp. 51-59. doi: $10.11648 /$ j.ajss.20210902.14

Received: June 7, 2021; Accepted: June 18, 2021; Published: June 23, 2021

\begin{abstract}
For school-age children to live with health and vitality in modern society, they need suitable physical strength and athletic ability, and measurements of physical strength and athletic ability that assesses those abilities are often considered essential. To address the problem of declining physical strength in recent years, City $\mathrm{O}$ has adopted an action plan. This action plan was established from a continuous 7-year survey of physique, physical strength, and athletic ability in fifth grade elementary school students and second year junior high school students. This study, to assess the effectiveness of City O's action plan, examined whether the trends in physical strength and athletic ability over those 7 years were rising or falling by analyzing the changes over time. The system adopted in this action plan is to measure the same items as in the physical strength and athletic ability survey conducted by the Ministry of Education, Culture, Sports, Science and Technology. From the results it is thought that an increase in exercise time was one factor in increased physical strength in City O. Behind this increase in exercise time was an increase in the percentage of children who belonged to a school team or sports club, and an increase in the percentage who responded that "Physical education class is fun." Above all was that action plans were included in the annual programs of all elementary and junior high schools in City O. and intentionally and systematically implemented. Therefore, in the system for increased physical strength and athletic ability based on the action plan of City O, exercise and physical activity time is ensured with participation in school teams or sports clubs. Furthermore, it is recognized that increasing the percentage of students who say that "physical education class is fun" was effective in raising the total score for physical strength and athletic ability over time. Particularly in second year junior high school girls, it would seem that the optimal valid physical strength of City O junior high school students could be advocated as a model for improving physical strength and athletic ability.
\end{abstract}

Keywords: Physical Strength, Athletic Ability, Exercise Habits, Changes over Time

\section{Introduction}

Nishijima $[1,2]$ has long argued the problem of declining physical strength in youth, but the decreased physical strength in school-age children has still not recovered to the level of around 1985. Similar reports are seen by Aoyama [3], Kagaya [4], and Wakita [5, 6]. Watanabe et al [7] has described the background that forms the basis of the problem of decreased physical strength using the most recent findings. That is, they show where decreases or increases in physical strength can be viewed as problems. Is it better that children's physical strength recover to the level in about 1985, or should we seek physical strength suited to modern society? This needs to be clarified. For example, standard physical strength is derived if the average for that population is calculated, but when it comes to optimal valid physical fitness, the question becomes optimal in terms of what? If one assumes that 1985 is the optimal model, then the optimal standard physical strength would of course be higher than at present. However, there are 
no grounds for assuming that the year that shows the highest physical strength in more recent years should be the model year. Optimal means the best suited, and the model for optimal valid physical fitness changes depending on whether we are seeking the optimal valid physical fitness national defense, the optimal valid physical fitness for sports, or the optimal valid physical fitness for ordinary living. Therefore, a clear view of the purpose of optimal valid physical fitness is needed.

In strength and athletic ability surveys conducted by the Ministry of Education, Culture, Sports, Science and Technology, the physical strength of children showed a decline in the years after 1999, when a new physical fitness test was introduced. That decline has now stopped, but physical strength is still at a low level compared with 1985. As reported by Kaga [8] and Hirakawa et al. [9], a polarization is seen between children who engage in active exercise and those who do not. Based on this background, "Exercise for fun and health" was added to physical education in the Elementary and Junior High School Curriculum Guidelines [10-13] and the High School Course of Study [14, 15]. Together with this, the name "gymnastics" in no longer used, changed instead to "exercise for strength development" in these classes. With these changes students who previously did not like to exercise started to like it. Treating classes as the "exercise for strength development" became important so that students would incorporate exercise in their daily lives. Starting in April 2002, the Ministry of Education, Culture, Sports, Science and Technology also enacted a complete 5-day school week system. The Organization for Economic Cooperation and Development (OECD) enacted the Program for International Student Assessment (PISA) once every three years starting from 2000. From the results of these PISA surveys, the decline in academic ability became an issue and since the 2007 academic year the Ministry of Education, Culture, Sports, Science and Technology has been conducting national surveys of academic ability and learning in sixth grade elementary school students and third year junior high school students. National surveys of physical strength and athletic ability, exercise habits, and other factors have also been conducted since 2008 in fifth grade elementary school students and second year junior high school students, and rankings have been published of assessments by total physical fitness score by prefecture.

Following on the above, use of the physical strength and athletic ability surveys by the Ministry of Education, Culture, Sports, Science and Technology has led to policies to counter the decline in physical strength in children. Itani [16] has said that this started with the Central Council for Education's report "Comprehensive Policy for Improving Physical Fitness in Children, 2002," after which the Ministry of Education, Culture, Sports, Science and Technology and regional educational committees began various efforts in accordance with this report. In City O, the physical strength and athletic ability ranking was at a low level nationally, and the city formulated the "Plan to enhance physical development in children" in the 2008 school year. They then began to implement a policy to improve physical fitness after receiving a mandate from the Ministry of Education, Culture, Sports, Science and Technology in the 2009 school year. At the time this policy was implemented, Mimura et al $[17,18]$ carefully examined the physical strength and athletic ability of young children and students in City O from 1986 to 1988, and found a trend for declining athletic ability, centered on physical coordination, in elementary school students, and inferior agility, whole-body endurance, and general athletic ability in junior high and high school students. From this a foundation for the action plan was created.

However, as we indicated at the beginning, there has been little substantive debate on what makes decreases or increases in physical strength among children a problem, or on the balance of physical growth and development and the balance of body composition, even while decreases in physical strength have been indicated. Therefore, a clear view of what it is that physical strength is needed for is necessary. In fact, the level of physical strength of people who achieve exceptional results in competitive sports is quite high, whereas the physical strength of people who exercise little is a vulnerability in that they may easily fall and injure themselves in daily living, and are susceptible to fractures if they do fall. Of course, the view that a decline in the physical strength of children is a problem is an example of the former. In other words, what is needed is the optimal valid physical fitness to live in modern society.

This is why City O's educational committee, in formulating the city's action plan, had already carried out a "project to improve children's physical fitness" over seven years from 2013 to 2019 with the involvement of Mimura and Abe et al [25], based on the reports of Mimura et al [17, 18]. These annual reports [19-25] show the results of surveys of physical strength and athletic ability in fifth grade elementary school students and second year junior high school students in City O. However, with only the results of simple fact-finding surveys it is not possible to verify what the physical fitness improvement policies are attempting to achieve. These reports contained the results of questionnaire surveys on exercise habits and other matters, and they make it possible for us see the relationship between the physical activity environment and physical fitness in the children of City O. If the action plans such as that of City $\mathrm{O}$ can be examined over time, the grounds for physical strength and athletic ability improvement policies can be clarified. In other words, the grounds for the optimal valid physical fitness to survive in modern society of the children of City $\mathrm{O}$ can be discovered.

In this study we carefully examined the City $\mathrm{O}$ action plan over seven years and analyzed whether the trends in physical strength and athletic ability in fifth grade elementary school students and second year junior high school students rose or fell with time. We analyzed the relationship between the exercise habit data contained in the action plan and the rising or falling trends in physical strength. Then, by examining the effectiveness of the physical strength improvement system, we attempted to determine the optimal valid physical fitness and athletic ability for children in City $\mathrm{O}$. 


\section{Methods}

\subsection{Subjects}

The subjects were 130,279 fifth grade elementary school boys and girls and 116,102 second year junior high school boys and girls.

Table 1. Number of subjects and statistical values of physical characteristics from 2013 to 2019 years.

\begin{tabular}{|c|c|c|c|c|c|c|c|c|c|c|c|}
\hline \multirow[b]{2}{*}{ year } & \multirow[b]{2}{*}{$\begin{array}{l}\text { school } \\
\text { type }\end{array}$} & \multicolumn{4}{|c|}{ city $\mathrm{O}$ number total } & \multicolumn{2}{|l|}{ Hight (cm) } & \multicolumn{2}{|l|}{ Weight (kg) } & \multicolumn{2}{|c|}{ fat children-slim children $(\%)$} \\
\hline & & $\begin{array}{l}\text { number of } \\
\text { school }\end{array}$ & subjec & & total & $\begin{array}{l}\text { city } O \\
\text { Means } \pm \text { SD }\end{array}$ & $\begin{array}{l}\text { National } \\
\text { Means } \pm \text { SD }\end{array}$ & $\begin{array}{l}\text { city } O \\
\text { Means } \pm \text { SD }\end{array}$ & $\begin{array}{l}\text { National } \\
\text { Means } \pm \text { SD }\end{array}$ & $\begin{array}{l}\text { city } O \\
\text { body fat }\end{array}$ & $\begin{array}{l}\text { city } O \\
\text { body slim }\end{array}$ \\
\hline \multirow{4}{*}{2013} & elementary & \multirow{2}{*}{306} & boys & 9,647 & \multirow{2}{*}{18,820} & $138.9 \pm 6.1$ & $138.9 \pm 6.1$ & $34.3 \pm 7.3$ & $34.0 \pm 7.2$ & $10.6 \%$ & $2.3 \%$ \\
\hline & school & & girls & 9,173 & & $140.0 \pm 6.7$ & $140.1 \pm 6.7$ & $34.0 \pm 6.8$ & $33.9 \pm 6.8$ & $8.3 \%$ & $2.1 \%$ \\
\hline & junior high & \multirow{2}{*}{138} & boys & 8,592 & \multirow{2}{*}{16,793} & $159.9 \pm 7.9$ & $159.6 \pm 7.7$ & $48.8 \pm 9.7$ & $48.6 \pm 9.5$ & $7.7 \%$ & $2.1 \%$ \\
\hline & school & & girls & 8,201 & & $155.1 \pm 5.4$ & $154.8 \pm 5.4$ & $46.6 \pm 7.3$ & $46.7 \pm 7.3$ & $5.9 \%$ & $4.1 \%$ \\
\hline \multirow{4}{*}{2014} & elementary & \multirow{2}{*}{308} & boys & 9,662 & \multirow{2}{*}{18,940} & $138.8 \pm 6.2$ & $138.9 \pm 6.1$ & $34.0 \pm 7.3$ & $34.0 \pm 7.3$ & $10.3 \%$ & $2.6 \%$ \\
\hline & school & & girls & 9,278 & & $140.0 \pm 6.7$ & $140.1 \pm 6.7$ & $34.0 \pm 6.9$ & $33.9 \pm 6.9$ & $7.7 \%$ & $2.5 \%$ \\
\hline & junior high & \multirow{2}{*}{141} & boys & 8,867 & \multirow{2}{*}{17,368} & $159.9 \pm 7.9$ & $159.7 \pm 7.7$ & $48.8 \pm 9.7$ & $48.6 \pm 9.6$ & $8.3 \%$ & $2.2 \%$ \\
\hline & school & & girls & 8,501 & & $155.0 \pm 5.4$ & $154.9 \pm 5.4$ & $46.3 \pm 7.2$ & $46.7 \pm 7.4$ & $5.9 \%$ & $4.5 \%$ \\
\hline \multirow{4}{*}{2015} & elementary & \multirow{2}{*}{303} & boys & 9,479 & \multirow{2}{*}{18,408} & $138.9 \pm 6.1$ & $138.8 \pm 6.1$ & $34.1 \pm 7.1$ & $33.9 \pm 7.2$ & $9.5 \%$ & $2.2 \%$ \\
\hline & school & & girls & 8,929 & & $140.0 \pm 6.7$ & $140.0 \pm 6.8$ & $34.0 \pm 6.9$ & $33.8 \pm 6.8$ & $8.0 \%$ & $2.5 \%$ \\
\hline & junior high & \multirow{2}{*}{140} & boys & 9,179 & \multirow{2}{*}{17,566} & $159.8 \pm 8.0$ & $159.8 \pm 7.7$ & $48.6 \pm 9.7$ & $48.5 \pm 9.5$ & $8.0 \%$ & $2.7 \%$ \\
\hline & school & & girls & 8,387 & & $155.1 \pm 5.4$ & $154.9 \pm 5.4$ & $46.1 \pm 7.0$ & $46.7 \pm 7.3$ & $5.3 \%$ & $4.3 \%$ \\
\hline \multirow{4}{*}{2016} & elementary & \multirow{2}{*}{292} & boys & 9,019 & \multirow{2}{*}{17,667} & $138.8 \pm 6.2$ & $138.8 \pm 6.2$ & $34.1 \pm 7.3$ & $34.0 \pm 7.2$ & $9.6 \%$ & $2.4 \%$ \\
\hline & school & & girls & 8,648 & & $140.0 \pm 6.8$ & $140.1 \pm 6.8$ & $34.0 \pm 6.9$ & $33.9 \pm 6.9$ & $7.6 \%$ & $2.5 \%$ \\
\hline & junior high & \multirow{2}{*}{131} & boys & 8,600 & \multirow{2}{*}{16,757} & $160.4 \pm 7.8$ & $160.0 \pm 7.7$ & $49.0 \pm 9.7$ & $48.6 \pm 9.6$ & $8.0 \%$ & $3.1 \%$ \\
\hline & school & & girls & 8,157 & & $155.1 \pm 5.4$ & $154.9 \pm 5.4$ & $46.3 \pm 7.0$ & $46.7 \pm 7.3$ & $5.5 \%$ & $4.0 \%$ \\
\hline & elementary & 200 & boys & 9,614 & 18640 & $138.9 \pm 6.2$ & $138.9 \pm 6.2$ & $34.1 \pm 7.4$ & $34.1 \pm 7.2$ & $10.0 \%$ & $3.0 \%$ \\
\hline 2017 & school & 290 & girls & 9,035 & 18,049 & $140.1 \pm 6.7$ & $140.1 \pm 6.8$ & $33.9 \pm 6.8$ & $33.9 \pm 6.9$ & $7.5 \%$ & $2.6 \%$ \\
\hline 2017 & junior high & 131 & boys & 8,306 & & $160.1 \pm 8.0$ & $160.0 \pm 7.7$ & $48.7 \pm 9.8$ & $48.6 \pm 9.5$ & $8.2 \%$ & $3.2 \%$ \\
\hline & school & 131 & girls & 8,056 & 16,362 & $155.1 \pm 5.4$ & $154.9 \pm 5.4$ & $46.4 \pm 7.2$ & $46.7 \pm 7.2$ & $5.7 \%$ & $4.5 \%$ \\
\hline & elementary & 290 & boys & 9,672 & 18940 & $139.0 \pm 6.3$ & $138.9 \pm 6.2$ & $34.4 \pm 7.5$ & $34.2 \pm 7.3$ & $11.3 \%$ & $2.5 \%$ \\
\hline 2018 & school & 290 & girls & 9,268 & 10,940 & $140.1 \pm 6.8$ & $140.1 \pm 6.8$ & $34.1 \pm 6.9$ & $34.0 \pm 6.9$ & $7.9 \%$ & $2.7 \%$ \\
\hline 2018 & junior high & 131 & boys & 8,179 & & $160.3 \pm 7.8$ & $160.1 \pm 7.7$ & $49.0 \pm 9.5$ & $48.7 \pm 9.5$ & $8.1 \%$ & $2.9 \%$ \\
\hline & school & 131 & girls & 7,705 & 15,884 & $155.1 \pm 5.4$ & $154.9 \pm 5.4$ & $46.3 \pm 7.1$ & $46.6 \pm 7.2$ & $5.7 \%$ & $4.9 \%$ \\
\hline & elementary & 280 & boys & 9,735 & & $138.9 \pm 6.1$ & $138.9 \pm 6.2$ & $34.5 \pm 7.4$ & $34.4 \pm 7.4$ & $11.3 \%$ & $2.6 \%$ \\
\hline 2010 & school & 289 & girls & 9,120 & 18,855 & $140.1 \pm 6.9$ & $140.1 \pm 6.8$ & $34.2 \pm 6.9$ & $34.1 \pm 6.9$ & $8.4 \%$ & $2.5 \%$ \\
\hline 2019 & junior high & & boys & 7,867 & & $160.2 \pm 7.9$ & $160.1 \pm 7.7$ & $49.2 \pm 9.9$ & $48.9 \pm 9.7$ & $8.9 \%$ & $2.8 \%$ \\
\hline & school & 130 & girls & 7,505 & 15,372 & $155.1 \pm 5.4$ & $154.9 \pm 5.4$ & $46.5 \pm 7.1$ & $46.8 \pm 7.3$ & $5.6 \%$ & $3.9 \%$ \\
\hline & elementary & 2078 & boys & 66,828 & & $138.9 \pm 6.2$ & $138.9 \pm 6.1$ & $34.2 \pm 7.3$ & $34.1 \pm 7.3$ & $10.4 \%$ & $2.5 \%$ \\
\hline Total & school & $20 / 8$ & girls & 63,451 & $130,2 / 9$ & $140.0 \pm 6.8$ & $140.1 \pm 6.8$ & $34.0 \pm 6.9$ & $33.9 \pm 6.9$ & $7.9 \%$ & $2.5 \%$ \\
\hline means & junior high & 0 & boys & 59,590 & 116 & $160.1 \pm 7.9$ & $159.9 \pm 7.7$ & $48.9 \pm 9.7$ & $48.6 \pm 9.6$ & $8.2 \%$ & $2.7 \%$ \\
\hline & school & 942 & girls & 56,512 & 110,102 & $155.1 \pm 5.4$ & $154.9 \pm 5.4$ & $46.4 \pm 7.1$ & $46.7 \pm 7.3$ & $5.7 \%$ & $4.3 \%$ \\
\hline
\end{tabular}

\subsection{Measurements of Physique, Physical Strength and Athletic Ability}

Height and weight were measured for physique. Measurements of physical strength and athletic ability included the eight items of grip strength, sit-ups, sit-and-reach, repeated side steps, $20 \mathrm{~m}$ shuttle run, $50 \mathrm{~m}$ sprint, standing long jump, and softball throw (in junior high school, handball throw). The mean values, standard deviations, total physical fitness score, and total exercise time per week were calculated. These measurements were done in accordance with national surveys of physical fitness, athletic ability, and exercise habits [26, 27]. The results of each measurement were classified in five levels of Groups A-E in order from highest total assessment, according to the assessment criteria of the new physical fitness test implementation guidelines.

\subsection{Survey of Exercise Habits}

A questionnaire survey was conducted in line with the schoolchildren survey form of the national survey of physical fitness, athletic ability, and exercise habits [26, 27].

\subsection{City O Action Plan}

The City $\mathrm{O}$ education committee started a committee to promote children's physical fitness, with members including experienced educators, top athletes, representatives of educational research societies for kindergarten, elementary school, and junior high school, and representatives of parent-teacher associations. The committee presented the following measures. They formulated a "Strength development action plan" that was included in schools' annual programs for the intentional and systematic implementation of exercise. The results for each school were analyzed using a verification sheet, 
results and issues were clarified, and attempts were made to increase physical strength with a PDCA cycle. The "results and issues" from annual feedback each year were posted on the website of each school. Starting in 2015, action plans were also implemented in kindergartens. Following on this, four elementary schools and two junior high schools were designated "Physical fitness improvement model schools." The results of measures undertaken to effectively improve physical fitness were shared with all schools in workshops and other sessions. Furthermore, in coordination with the Economic Strategy Bureau, athletes and coaches who had participated in international competitions such as the Olympics or World Cup encouraged children to dream, using "Dream Classes" in which top athletes visited schools and communicated to the children what a wonderful thing it is to strive to achieve one's dreams.

\subsection{Statistical Analysis}

The statistical analysis was done using SPSS for Windows (ver. 25.0, IBM), with a statistical significance level of $5 \%$. In handling the data from this study, letters of consent were exchanged between the president of Osaka Seikei University and the superintendent of the City O Education Committee on the loan of the "results data from the surveys on physical fitness, athletic ability, and exercise habits in fifth grade elementary school students and second year junior high school students in City O over the seven years from the 2013 to 2019 school years," and approval was obtained.

\section{Results}

\subsection{Changes over Time in Physique, Physical Strength and Athletic Ability}

The height of fifth grade elementary school girls showed higher values than that of boys, while weight tended to show higher values in boys than in girls $(\mathrm{p}<0.05)$. In second year junior high school students, boys tended to show higher values than girls in both height and weight $(\mathrm{p}<0.05)$. Both elementary and junior high school boys and girls in this study showed trends similar to the national average for height and weight, and that did not change over time.

Looking at the changes over seven years in the total score for physical strength and athletic ability, little change was seen in fifth grade elementary school boys, from $52.3 \pm 9.0$ to $52.5 \pm 9.2$, but a rising trend, from $52.8 \pm 8.3$ to $54.5 \pm 8.7$, was seen in girls $(p<0.05)$. In second year junior high school boys, a slight rising trend was seen from $40.3 \pm 9.4$ to $41.0 \pm 10.0$ $(p<0.05)$, while in girls a clear rising trend was seen, from $47.0 \pm 10.7$ to $50.1 \pm 10.9 \quad(\mathrm{p}<0.05)$. Those trends were particularly striking in girls in both elementary school and junior high school (Figures 1,2).

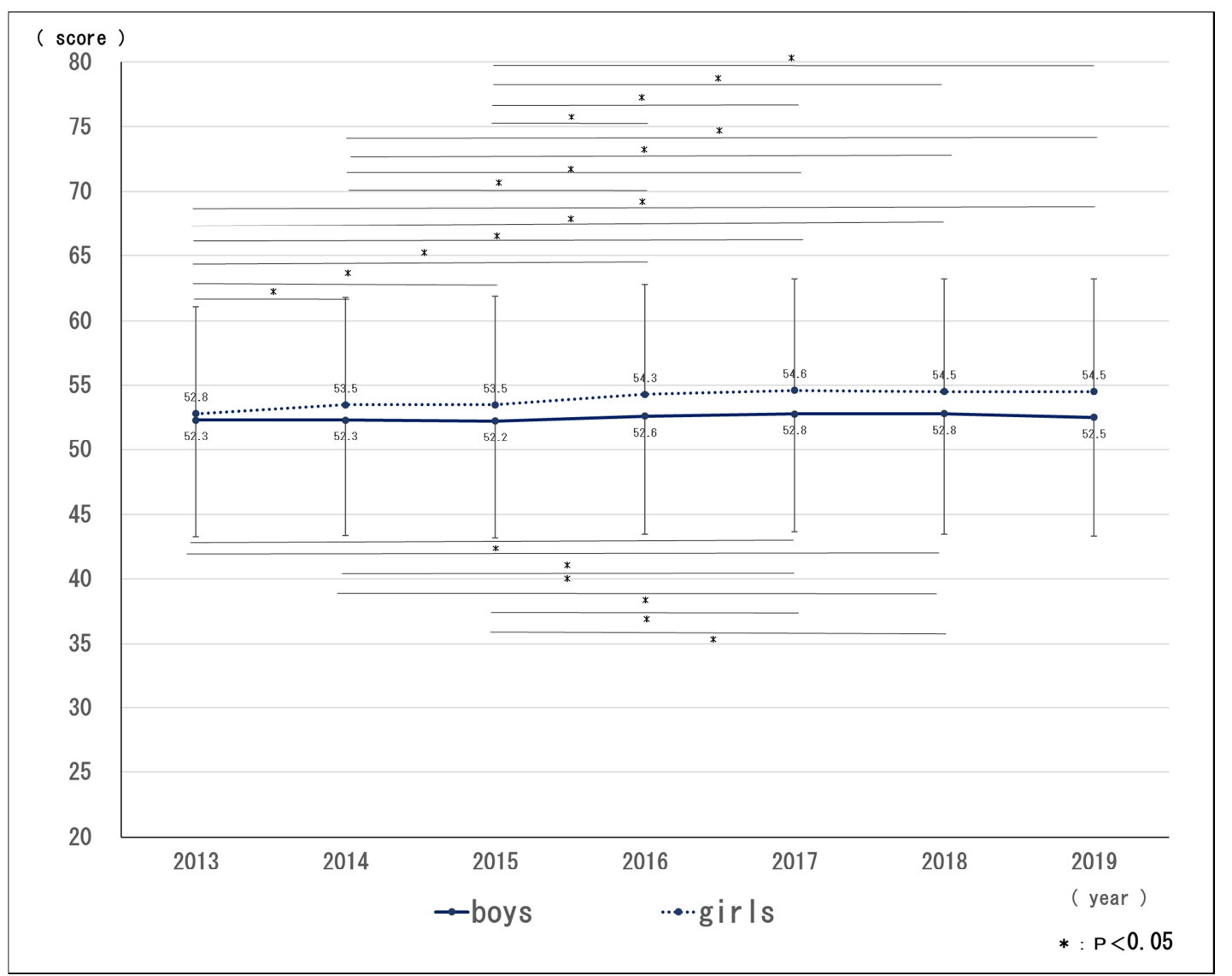

Figure 1. Annual trend of mean and standard deviation in the total physical fitness score of boys and girls (5th grade elementary school). 
Ken-ichi Watanabe et al: $\quad$ Effectiveness of a Physical Strength Improvement System in School-Age Children Based on the Action Plan of City O

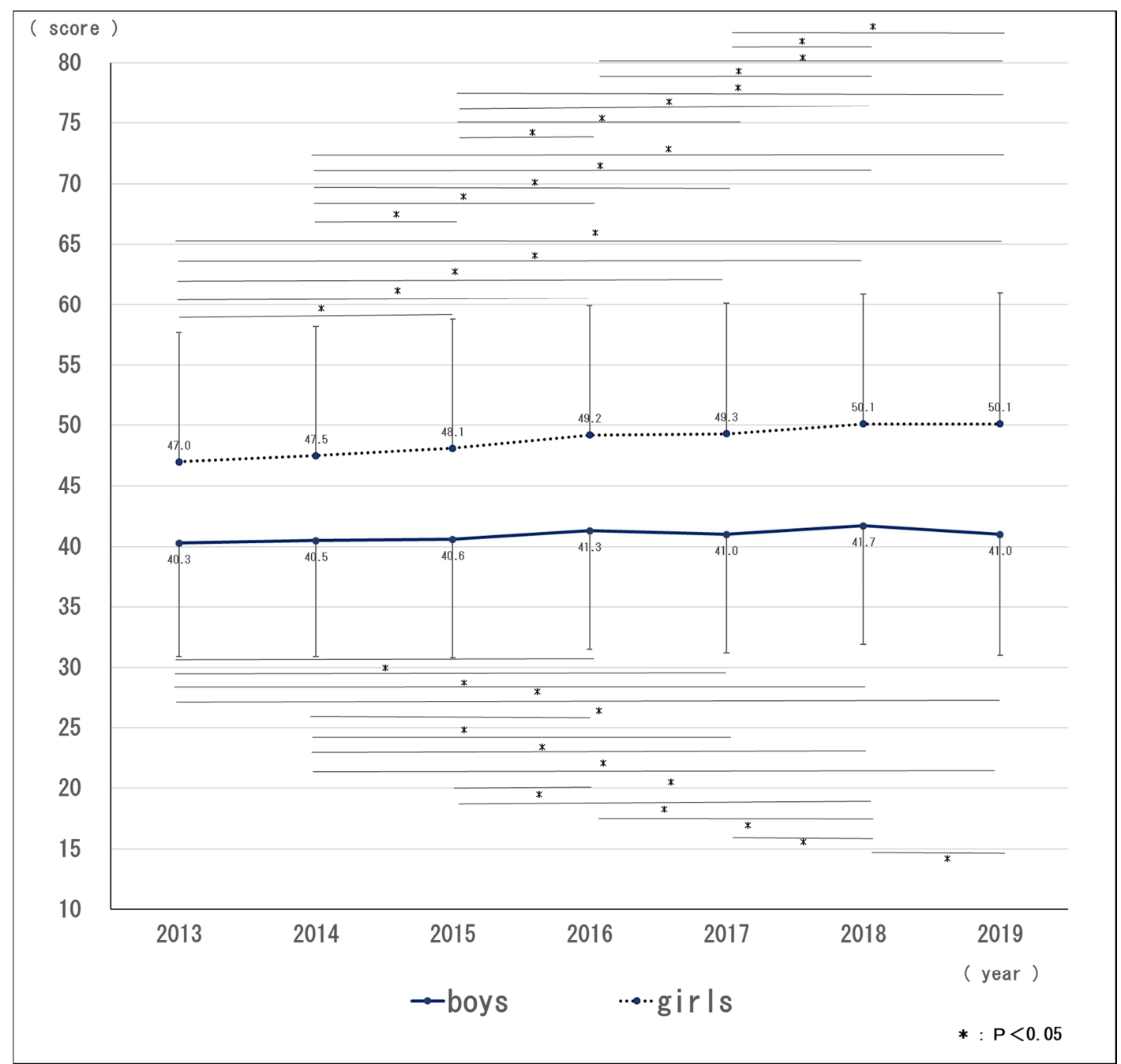

Figure 2. Annual trend of mean and standard deviation in the total physical fitness score of boys and girls (2nd grade junior high school).

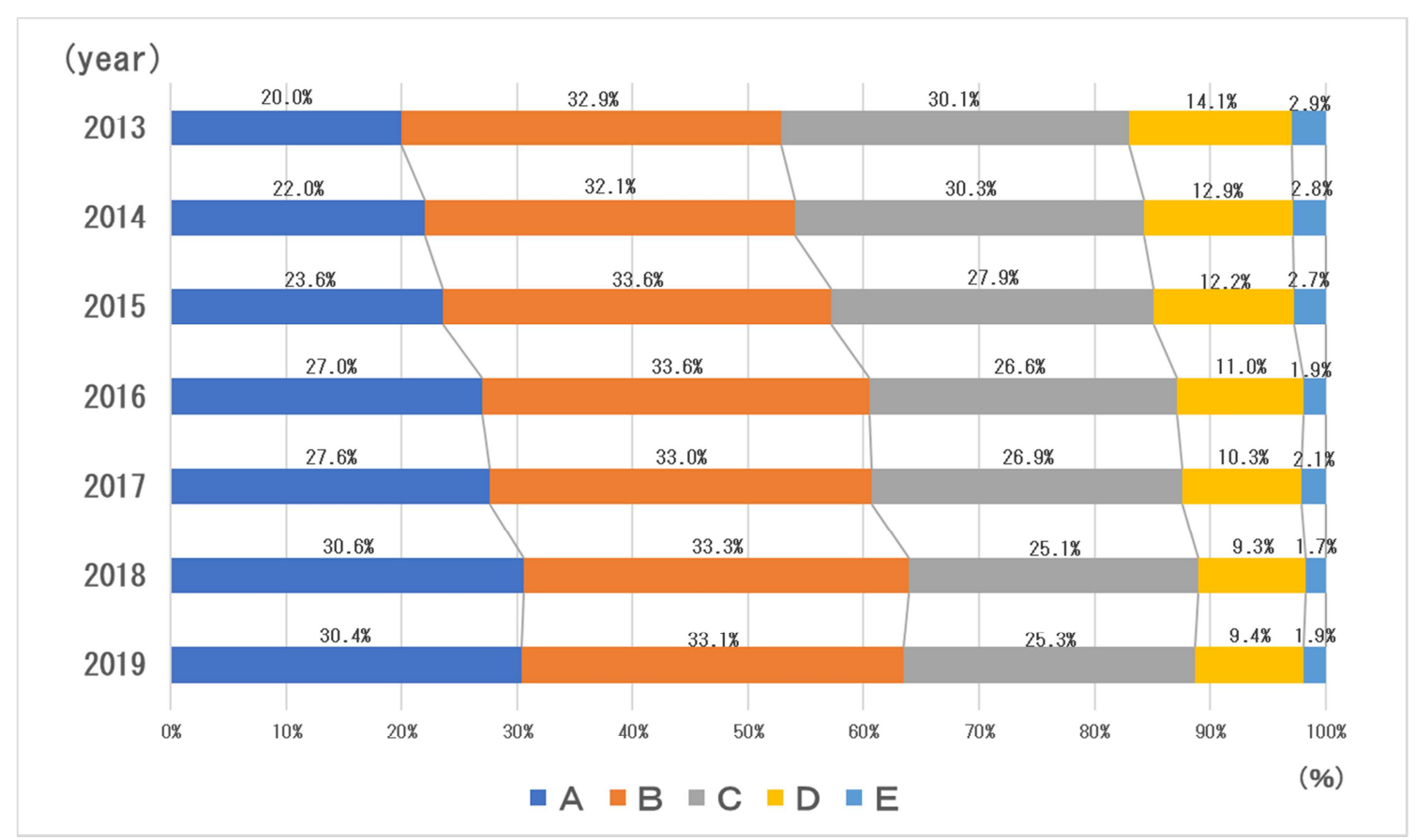

Figure 3. The percentage (\%) of comprehensive evaluation of physical fitness girls (2nd grade junior high school). 


\subsection{Trends over Time in Overall Assessment of Physical Strength and Athletic Ability}

In Figure 3, total scores for physical strength and athletic ability in second year junior high school students are classified into Groups A, B, C, D, and E in order of score rank, and that classification status is shown over time. The percentage of Groups A and B, which have high overall scores, increased gradually from $52.9 \%$ in 2013 to $63.5 \%$ in 2019 , an increase of 10.6 points. In contrast, the percentage of Groups D and E, which have low overall scores, decreased gradually from $17.0 \%$ in 2013 to $11.3 \%$ in 2019 . Although not shown in the Figure, similar gradually increasing trends were seen in Groups A and B of fifth grade elementary school boys, with a 2.4 -point increase from $28.8 \%$ to $31.2 \%$, and girls, with an 8.7-point increase from $28.4 \%$ to $37.1 \%$, and in second year junior high school boys, with a 4.5-point increase from $26.3 \%$ to $30.8 \%$. In contrast, Groups D and E showed little change over time in fifth grade elementary school boys, with a 0.2 -point decrease from $35.7 \%$ to $35.5 \%$. However, they showed a gradual decrease in fifth grade elementary school girls of 6.8 points, from $33.6 \%$ to $26.8 \%$, and in second year junior high school boys of 2.6 points from
$33.9 \%$ to $31.3 \%$.

\subsection{Effectiveness of System to Raise Physical Strength and Athletic Ability Based on the Action Plan}

Figure 4 shows the relationship between total physical fitness score for second year junior high school girls and total exercise time per week in the 2019 school year. The results indicate that total physical fitness score became higher with increases in exercise time. Similar trends were seen with the annual changes for both elementary and junior high school boys and girls. Ensuring time for activity based on the action plan increased the total exercise time per week, and total physical fitness score showed an increasing trend over time. In junior high school girls in particular, an increase was seen in those who belonged to a school team or sports club. That is also a result of enacting the physical strength and athletic ability improvement system. In addition, the increased total exercise time per week from the action plan increased the percentage of students who said, "physical education class is fun" over time. This factor is also a result of enacting the physical strength and athletic ability improvement system.

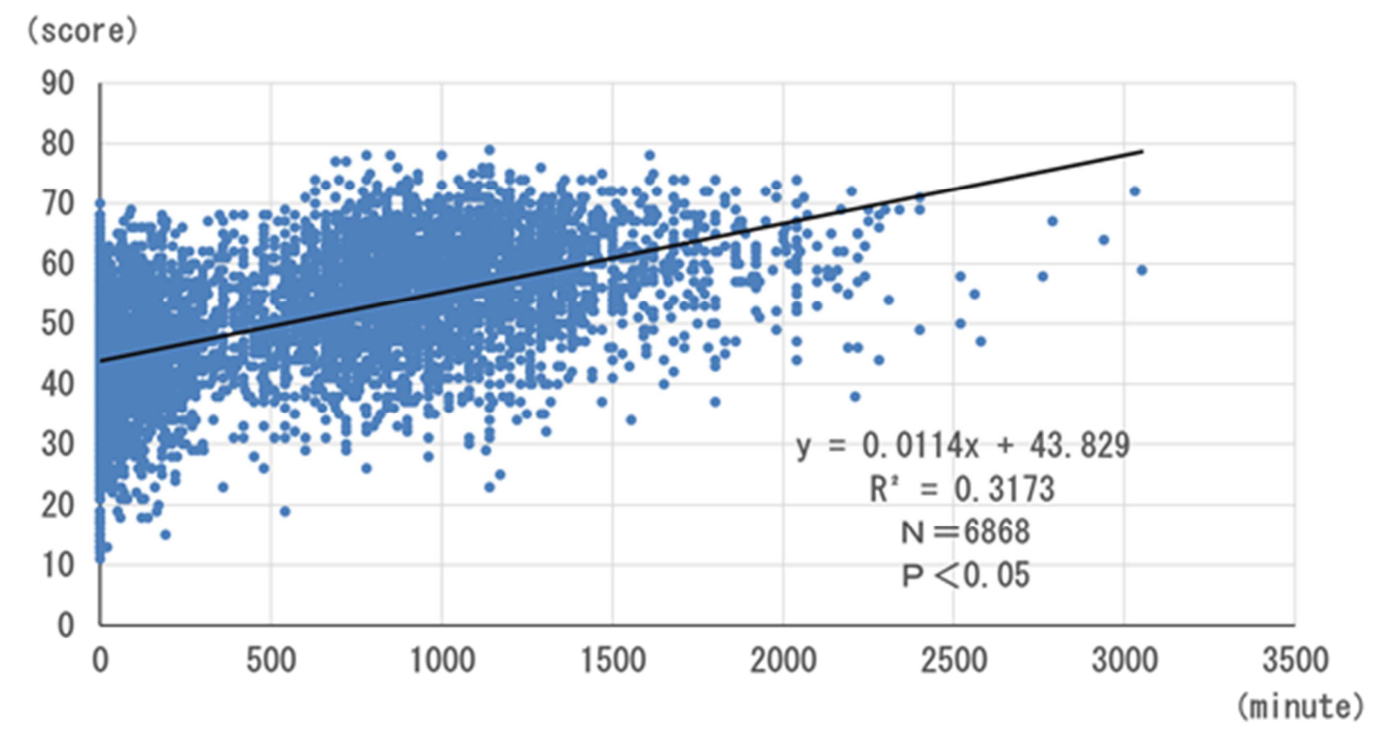

Figure 4. Relationship between total physical fitness score and total exercise time per week at 2nd grade girls of junior high school.

\section{Discussion}

Studies on physique and physical strength in the school years at the bulletin level are too numerous to mention. A majority of these studies tend to suggest the involvement of physique, especially height, in physical strength from findings based on correlation analyses of physique and physical strength. However, as has been indicated by Fujii [28], the correlation between height and physical strength is not especially strong, and height and athletic ability are independent phenomena. Of course, those studies have value as fact-finding surveys in the sense of grasping the level of physical strength and athletic ability in current schoolchildren. In this sense, analyzing the changes over time in physical strength and motor ability may be considered important in understanding the trends in physical ability in schoolchildren of recent years. Based on trends over time in physical strength and athletic ability, Nishijima [1,2] assessed the span from the increase in physical strength and athletic ability occasioned by the 1964 Tokyo Olympics until the current decreasing phase, with regard to the peak in the years of 1980-1985 and the decreasing trend in physical strength since then. He took this to be a declining trend in the physical strength of youth. In recent years, surveys of physical strength and athletic ability 
in the school years, even with the surveys of physical strength and athletic ability now implemented nationally in only the two years of the fifth grade of elementary school and the second year of junior high school, have in fact been affected by declining trends in physical strength.

In fact, the low level of physical strength and athletic ability in school-age children in City $\mathrm{O}$ were viewed as a problem, and measures to increase physical strength were undertaken. The trends in physical strength and athletic ability of fifth grade elementary school students and second year junior high school students in City $\mathrm{O}$ over seven years were judged from the ranking of the 47 prefectures in Japan. In the 2013 school year, fifth grade elementary school boys ranked $46^{\text {th }}$ and girls $45^{\text {th }}$, and second year junior high school boys ranked $42^{\text {nd }}$ and girls $39^{\text {th }}$. In the 2019 school year, the seventh year, fifth grade elementary school boys and girls both reached $43^{\text {rd }}$, while second year junior high school boys reached $38^{\text {th }}$ and girls $25^{\text {th }}$ Trends were thus seen in which they gradually approached the national average. This was striking especially in second year junior high school girls.

How much meaning is there is ranking total score for physical strength and athletic ability? There may be a risk of thinking of this as equivalent to the deviation score in academic ability. Certainly, academic ability, like physical strength and athletic ability, is a talent that cannot be seen. Methods to quantify those abilities include academic tests and tests of physical strength and athletic ability. For example, determining the relative level of academic ability is unavoidable for the purpose of a common test to select which students will enter university. However, ranking relative level of physical strength and athletic ability is a different phenomenon from the relative level of academic ability in that the purpose differs. The purpose of surveys of physical strength and athletic ability is not to rank relative level, but to evaluate whether school-age children have acquired physical ability compatible with their living environment or behavioral patterns. The purpose, as has also been pointed out by Naito [29], is to raise physical strength for healthy living, and understanding the current level of physical strength is important.

From the above, it is difficult to discuss rising trends with the slight rise in the ranking from the results of the changes over seven years in physical strength and athletic ability based on the action plan in this study. That is, such rankings show relative position, and even if the ranking of City $\mathrm{O}$ rises it could be just that the physical strength and athletic ability in other prefectures has decreased. Therefore, the trends over time in physical strength and athletic ability in City $\mathrm{O}$ need to be verified. Looking at the results shown in Figures 1-3, it seems clear that there is a rising trend in total score for physical strength and athletic ability. In particular, a striking increase is seen in second year junior high school girls. Moreover, judging from Figure 4, a strong correlation is shown between overall exercise time per week and total physical strength score. This is thought to be evidence showing that the increase in activity time due to the action plan contributed significantly to improved physical strength and athletic ability.
There is much information suggesting a relationship between activity time and physical strength and athletic ability. For example, Naka et al [30] and Shimada et al [31] suggested that ensuring sports activity time is important in maintaining and increasing physical strength. Findings showing a significant correlation between amount of exercise and physical strength have been derived by Hikihara et al [32], Sasayama et al [33], Kaga et al [34], Abe et al [35], Toda et al [36], and Maie [37]. Thus, it should be clear that exercising actively has an effect in improving physical strength. Kushima et al [38] reported that physical fitness was superior with longer practice time per week on school teams or sports clubs. At the same time, Watanabe and Mimura [39] reported that from doing exercise in physical education class, students come to like exercise and incorporate it in their daily lives, so that exercise time becomes longer. In this study, the efforts for physical education class at each school helped students to feel that the class was fun and they experienced the pleasure and enjoyment of exercising, from which it is thought that they tried to exercise more themselves. Thus, it is thought that exercise time was increased by increasing the percentage of students who say that "class is fun."

From the above, it seems that increased exercise time was a factor in the improved physical strength in City O. Behind the increase in exercise time is conjectured to be increases in the percentage of students who belonged to school teams or sports clubs, increases in the percentages who responded that "physical education class is fun," and more than anything the intentional and systematic implementation of the action plan in all elementary and junior high schools in City $\mathrm{O}$ with its positioning in their annual programs. However, the rising trend over time seen with the action plan in not only boys but also second year junior high school girls was probably due somewhat to the fact that while originally girls were less active than boys, the action plan promoted activity. Moreover, this is the period of late puberty for girls, and after the peak velocity in physical growth in girls. Since the time around the second year of middle school is the period approaching the developmental peak in physical strength, it can be inferred that this was tied to increased physical strength. In the system for increased physical strength and athletic ability based on the action plan of City $\mathrm{O}$, exercise and physical activity time is ensured with participation in school teams or sports clubs. In addition, it should be recognized that increasing the percentage of students who say that "physical education class is fun" was effective in raising the overall score for physical strength and athletic ability over time. Particularly in second year junior high school girls, it would seem that the optimal valid physical strength of City $\mathrm{O}$ junior high school students could be advocated as a model for improving physical strength and athletic ability.

\section{Conclusion}

This study examined the City $\mathrm{O}$ action plan over seven years, and analyzed whether there were rising or falling trends over time in physical strength and athletic ability of fifth grade 
elementary school students and second year junior high school students. The relationship between the exercise habit data included in the action plan and rising or falling trends was analyzed, and the effectiveness of the system for improving physical strength was verified. As a result, it is thought that increased exercise time was a factor in the improved physical strength in City O. Behind this increase in exercise time is conjectured to be increases in the percentage of students who belonged to school teams or sports clubs, increases in the percentages who responded that "physical education class is fun," and more than anything the intentional and systematic implementation of the action plan in all elementary and junior high schools in City $\mathrm{O}$ with its positioning in their annual programs. Therefore, in the system for increasing physical strength and athletic ability based on the action plan of City $\mathrm{O}$, exercise and physical activity time is ensured with participation in school teams or sports clubs. Furthermore, increasing the percentage of students who say that "physical education class is fun" was recognized to be effective in raising the overall score for physical strength and athletic ability over time. Particularly in second year junior high school girls, it would seem that the optimal valid physical strength of City $\mathrm{O}$ junior high school students could be advocated as a model for improving physical strength and athletic ability.

\section{References}

[1] T. Nishijima, "Declining trend in the physical strength of adolescents," Journal of Health, Physical Education and Recreation, Vol. 52, pp. 4-14, 2002.

[2] T. Nishijima, "Current status of physical strength in children," Child, Growth and Development, Vol. 1, pp. 13-22, 2003.

[3] S. Aoyama, "Loss of flexibility: results from sports tests", Sports Journal, Vol. 167, pp. 2-6, 1994.

[4] H. Kagaya, "What is the responsibility of adults for children's future: The current situation of children and the future of school physical education," Physical Education, Vol. 45 (14), pp. 36-39, 1997.

[5] H. Wakita, "Children's physical fitness is declining so much now," Journal of Health, Physical Education and Recreation, Vol. 46, pp. 286-291, 1996.

[6] H. Wakita, "Looking at Children's Crisis Situations: From Children's Physical Fitness and Motor Skills," Physical Education Vol. 45 (14), pp. 26-29, 1997.

[7] K. Watanabe, K. Fujii, K. Abe, Y. Kani and K. Mimura, "Analysis of Changes in Physical Strength over Time in Recent School-Age Students: Proposal for Multi-year Span Evaluation Chart with the O Model," American Journal of Sports Science, Vol. 9 (1), pp. 17-26, 2021.

[8] M. Kaga, K. Takahashi, Y. Kiyono, "Bipolarization of Frequency of Physical Activity in Childhood and Adolescence," The Journal of the Japan Pediatric Society, Vol. 108, pp. 625-634, 2004.

[9] K. Hirakawa, K. Takano, "Characteristics of boys and girls in the most superior and inferior groups on physical fitness with progress of bipolarization of physical fitness level," Research on Growth and Development, Vol. 37, pp. 57-67, 2008.

[10] Ministry of Education, Culture, Sports, Science and Technology, Elementary School Curriculum Guidelines, 1998.

[11] Ministry of Education, Culture, Sports, Science and Technology, Elementary School Curriculum and Instruction Guide for Physical Education, 1998.

[12] Ministry of Education, Culture, Sports, Science and Technology, Junior High School Curriculum Guidelines, 1998.

[13] Ministry of Education, Culture, Sports, Science and Technology, Secondary School Learning Guideline Commentary on Health Physical Education, 1998.

[14] Ministry of Education, Culture, Sports, Science and Technology, Courses of Study for High School Students, 1999.

[15] Ministry of Education, Culture, Sports, Science and Technology, High School Learning Guideline Commentary on Health and Physical Education, 1999.

[16] K. Itani, "Local political issues related to the "Improvement of children's physical fitness", focusing on conditions in metropolitan Tokyo and Osaka prefecture," Japan J. Phys. Educ. Hlth. Sport Sci, Vol. 60, pp. 429-448, 2015.

[17] K. Mimura, T. Kosaka, M. Sato, Y. Iriguchi, "Physical Fitness and Performance of School Children in Osaka City (I): in Primary School," Memoirs of Osaka Kyoiku University, Vol. 38 (1), pp. 75-85, 1989 a.

[18] K. Mimura, T. Kosaka, M. Sato, Y. Iriguchi, "Physical Fitness and Performance of School Children in Osaka City (II): in Junior High School and High School," Memoirs of Osaka Kyoiku University, Vol. 38 (2), pp. 265-2731989 b.

[19] Osaka City Education Committee, Report on the project to promote children's physical fitness in 2013, 2014.

[20] Osaka City Education Committee, Report on the project to promote children's physical fitness in 2014, 2015.

[21] Osaka City Education Committee, Report on the project to promote children's physical fitness in 2015, 2016.

[22] Osaka City Education Committee, Report on the project to promote children's physical fitness in 2016, 2017.

[23] Osaka City Education Committee, Report on the project to promote children's physical fitness in 2017, 2018.

[24] Osaka City Education Committee, Report on the project to promote children's physical fitness in 2018, 2019.

[25] Osaka City Education Committee, Report on the project to promote children's physical fitness in 2019, 2020.

[26] Ministry of Education, Culture, Sports, Science and Technology, 2013 National Survey on Physical Strength, Athletic Ability, and Exercise Habits, 2014.

[27] Ministry of Education, Culture, Sports, Science and Technology, 2014 National Survey on Physical Strength, Athletic Ability, and Exercise Habits, 2015.

[28] K. Fujii, "Exploration of Human Resource Elements of Sports Athletes -Sports Talent and Tall Height-", Production Management, Vol. 27 (1), pp. 161-169, 2020. 
[29] H. Naito, "Current state and issues in physical strength in children." National Strength and Conditioning Association Japan, Vol. 18 (1), pp. 2-6, 2011.

[30] H. Naka, S. Demura, "Influence of habitual exercise on physique and physical fitness in adolescent male students: From an examination of three-year longitudinal data," Japanese Society of Physical Education, Vol. 39 (4), pp. 287-303, 1994.

[31] S. Shimada, S. Demura, Y. Nagasawa, M. Minami, J. Matsuzawa, "Influence of The Difference of Continuous Exercise Enforcement Frequencies on Physique and Physical Fitness of Male Students at a National College of Technology: With an Examination of Three-Year Longitudinal Date," Japan Society of Physiological Anthropology, Vol. 11 (2), pp. 69-74, 2006.

[32] Y. Hikihara, K. Sasayama, K. Okishima, H. Mizuuchi, Y. Yoshitake, M. Adachi, K. Takamatsu, "Differences in the Relationship between Physical Activity and Physical Fitness in Early and Late Adolescence: Focusing on the "Quantitative" and "Intensity" Aspects of Physical Activity", Japanese Journal of Physical Fitness and Sports Medicine, Vol. 56, pp. 327-338, 2007.

[33] K. Sasayama, K. Okishima, H. Mizuuchi, M, Adachi, "Relationship of daily physical activity and fitness in elementary school children," The Japanese Journal of Physical Fitness and Sports Medicine, Vol. 58, pp. 295-304, 2009.

[34] M. Kaga, K. Hirata, K. Takahashi, Y, Kiyono, "The Effect of Daily Physical Activity on Physical Fitness and Motor Ability during Growth Period," The Journal of the Japan Pediatric Society, Vol. 106, pp. 655-664, 2002.

[35] K. Abe, K. Mimura, M. Tetsuguchi, S. Katsuno, "Daily Physical Activity among the Students in the Upper-grade of Elementary School", The Journal of Education and Health Science, V S. Toda, T. Watanabe, S. Tou, "Relationship between the amount of daily physical activity, physical fitness and physique of students in the upper grades of primary school," Japanese Journal of School Health, Vol. 49, pp. 348-362, 2007. ol. 50, pp. 106-114, 2004.

[36] S. Toda, T. Watanabe, S. Tou, "Relationship between the amount of daily physical activity, physical fitness and physique of students in the upper grades of primary school," Japanese Journal of School Health, Vol. 49, pp. 348-362, 2007.

[37] H. Maie, "A Relationship Between Daily Physical Activity and Physical Fitness of Children in Middle Grades of Elementary School," Tokyo Future University bulletin, Vol. 10, pp. 145-153, 2017.

[38] K. Kujima, T. Kuzuhara, N. Takamoto, M. Sakai, T. Komura, "Relationship between body position, physical fitness and lifestyle in junior high school students 1- A study on cross-sectional data of male students," Bulletin of Hiroshima Institute of Technology, Vol. 22, pp. 99-109, 1988.

[39] K. Watanabe, K. Mimura, "The present situation and problems of "fitness exercise" in high school Physical Education", Osaka Seikei University Bulletin, Vol. 5, pp. 313-322, 2019. 